Received 18th May 2017, Accepted 30th October2017

DOI: $10.1039 / c 7 c c 03862 c$

rsc.li/chemcomm

\title{
3D Assembly of Colloidal Nanoparticles into Gels and Aerogels: Function-led Design
}

\author{
Dan Wen and Alexander Eychmüller ${ }^{b}$
}

\begin{abstract}
Gels and aerogels derived from colloidal nanoparticles not only own the advantages of the traditional aerogels like ultralow density, large surface area and high porosity, but also retain some of the unique properties of the nanoparticles. These characteristics endow such new types of materials with the possibility of promising applications. In this review, we focus on the function-led design of aerogels from the 3D assembly of OD spherical particles, 1D nanowires, and 2D nanosheets, and especially their applications in catalysis, sensing, optoelectronics, pollutants adsorbent/filtration, and beyond.
\end{abstract}

\section{Introduction}

Aerogels are highly porous inorganic superstructures with extremely low-density and high inner surface area, bridging the macro and nano dimensions in their properties, which make them very attractive in applications such as catalysis, thermoresistors, piezoelectrics, adsorbents, and sensors. ${ }^{1,2}$ The chemistry of the aerogel synthesis originated from the pioneering work of Steven Kistler from the early $1930 \mathrm{~s}^{3}$ and was further developed from the late $1960 \mathrm{~s}^{4}$. In the past decades, the composition of aerogel materials has been limited to silica and other metal oxides together with their mixtures. This thus restricts the functionality of the aerogels to achieve the properties demanded and subsequently their applications. Until recently, special attention has been paid to create oxide-free functional aerogels, based mainly on the assembly of discrete inorganic nanoparticles (NPs) to form gel networks via a bottom-up route, which may open enormous opportunities for nanotechnology and material science. , $^{5}$

On the basis of the knowledge of the sol-gel process for oxide materials, the approach utilizing NPs as building blocks for a selfsupporting three-dimensional (3D) porous network has been developed. Brock and co-workers firstly reported on the photoinduced controlled destabilization of semiconductor nanocrystals (CdS) for the formation of nanowires and networks, which was soon extended to $\mathrm{PbS}, \mathrm{ZnS}$, and $\mathrm{CdSe} .^{7,8}$ Since then, considerable research has been performed on the 3D assembly of various colloidal NPs composed of metal chalcogenides or pnictides, metals and metal oxides. ${ }^{9-13}$ As mentioned above, the first NP-aerogels were composed of $\mathrm{CdS}$ and CdSe, showing a certain blue shift in the absorption typical for quantum-confined NP building blocks but

\footnotetext{
${ }^{a}$ Center for Nano Energy Materials, School of Materials Science and Engineering, Northwestern Polytechnical University, Xi'an 710072, China

E-mail: wendan1020@gmail.com

${ }^{b}$ Physical Chemistry, TU Dresden, Bergstrasse 66b, 01062 Dresden, Germany E-mail: alexander.eychmueller@chemie.tu-dresden.de
}

appeared to be barely emitting. $7,8,14$ The maintaining or extent of the characteristic quantum confinement effects of their building blocks lead to applications in optoelectronics. ${ }^{15,16}$ Furthermore, the soft Lewis base characteristics of the framework and the presence of an interconnected pore-network result in unique sorption properties that may be suitable for environmental remediation or gas-separation. ${ }^{17,18}$ The first report on noble metal aerogels originating from the corresponding NPs has been pioneered by our group. These monometallic ( $\mathrm{Au}, \mathrm{Ag}, \mathrm{Pt})$ and bimetallic ( $\mathrm{Au} / \mathrm{Ag}$ and $\mathrm{Pt} / \mathrm{Ag}$ ) gels and aerogels exhibit an average density 1-2 orders of magnitude lower than that of metallic foams. ${ }^{19,20}$ Coupling of the catalytic and photonic properties of the noble metal NPs to the large surface area and high interconnected porosity in the aerogel samples is promising for a broad range of applications in catalysis and sensing. Niederberger et al. developed surface-functionalized oxide NPs of a few nanometers in diameter connected by oriented attachment into 3D aerogel monoliths. ${ }^{21,22}$ Such aerogels overcome the natural quality of amorphous oxide aerogels from the traditional sol-gel method and offer a large variety of interesting properties like ultralightness, full crystallinity, translucence, high porosity, and large surface area for promising photocatalysis. Overall, the resultant new types of aerogels remarkably afford the physicochemical features of the NPs in addition to the typical properties of porous materials and enrich the crystallinity and composition of aerogels.

Current research efforts have been mainly devoted to the development of synthesis strategies for NP-based aerogels to construct fine 3D porous materials, however, exploring their potential applications is still a young field. Nowadays, the interest has turned more and more to the function-led design of the NPbased aerogels for their promising task-specific applications. According to the perspective review ${ }^{23}$ and the comprehensive handbook regarding such new kinds of aerogels ${ }^{24}$ in about 2011, here we will focus on the function-led design of aerogels from colloidal NPs (i.e., OD, 1D and 2D particles). We will start from a general introduction of 3D assembly of NPs into gels and aerogels, and mainly highlight their applications in catalysis, sensing, 
optoelectronics, pollutant adsorbents/filter, and beyond mainly in the past five years. Finally, the future trends and perspectives for the function-led design of NP-based aerogels for specific tasks are discussed.

\section{Assembly of Nanoparticles into gels and aerogels}

Strictly speaking, to understand NP-based aerogels, it is necessary to first understand the 3D assembly of colloidal NPs. In the following, we will first discuss the controllable destabilization of the colloidal building blocks, the core of the NP-based aerogels, to construct the fine porous network. A common strategy of the destabilization is partial removal of the surface stabilizing agent from the NPs, which may be achieved by different methods including oxidation of surface ligands, reduction of electrostatic stabilization by adjusting the ionic strength of the solution, depleting the shell of ligands through suitable solvent washing, heating the colloidal solution to dissociate or decompose the ligands, and increasing the concentration of the sols. Notably,

photo- or chemical oxidation of the surface thiolate groups to remove the capping agents of quantum dots (QDs) has been successfully and widely applied in the formation of QD-based gel networks whilst extending to metal NP-gels. ${ }^{19,25}$ Alternatively, the cross-linkers between surface organic/inorganic functionalities of NPs via coordination or electrostatic interactions by a metalassisted route and covalent bonding has also been adopted to induce self-assembly of NPs into inorganic aerogels. For instance, when tetrazoles were employed as the capping agents in the NP synthesis, 3D gel structures of metal, semiconductor and hybrid metal-semiconductor can be formed in solution by the controlled gelation of pre-synthesized NPs due to the linking of tetrazoleligands via the complexation with divalent cations owing to the electron donating ability of the tetrazole molecules. ${ }^{26-28}$ In addition, the controllable destabilization is sometimes spontaneously inferred from the in situ reduction of NPs. The salts generated during the synthesis are suspected to play an important role in the gel formation. They increase the ionic strength of the solution and decrease the electrostatic repulsion between the primary NPs.

The general approach leading to the fabrication of NP-aerogels is based on their controllable destabilization as discussed above, followed by supercritical solvent removal as described below (Scheme 1). Such wet gels obtained from the 3D assembly of various NPs are commonly dried in a critical point drier where the

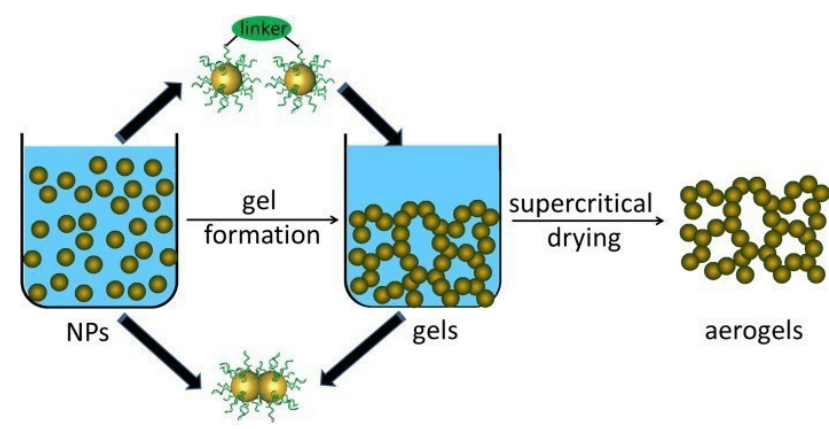

Scheme 1. Schematic illustration of the 3D assembly of colloidal NPs into gels and aerogels.
3D porous structures of very delicate species are preserved from the destructive influence of surface tension and turbulences appearing during drying under ambient conditions. ${ }^{29}$ This technique is based on the exchange of the interstitial solvent with liquid $\mathrm{CO}_{2}$, bringing the $\mathrm{CO}_{2}$ to its critical state, and its removal by reducing the pressure while maintaining the temperature above the critical point (around $31{ }^{\circ} \mathrm{C}$ ). It is noted that a solvent exchange to $\mathrm{CO}_{2}$ in the drying process, compared to be performed from methanol, acetone, or similar solvents originally used as media for the gelation (around $240{ }^{\circ} \mathrm{C}$ or even higher), reduce the processing time at low temperatures. ${ }^{4}$

Recently, new technologies regarding the 3D assembly of colloidal NPs via a physical concept have been developed. Highly porous inorganic nanowire hydrogels/aerogels can be obtained by assembling the nanowires into a cross-linked network from their colloidal suspensions at the transition from semidilute to isotropic concentrated regimes. ${ }^{30}$ Aerogels of metals, oxides, and semiconductors have been constructed by an ice-templating assembly from $\mathrm{Au}, \mathrm{Ag}, \mathrm{Pd}$, and Pt NPs, $\mathrm{Ag} / \mathrm{Cu}$ nanowires, $\mathrm{Fe}_{2} \mathrm{O}_{3} \mathrm{NPs}$, and $\mathrm{MnO}_{2}$ nanoflowers, respectively. ${ }^{31-34}$ This approach is basedon freezing colloidal NPs and subsequent freeze drying, which is highly versatile and applicable for metal, metal oxide, and semiconductor NPs, and no impact of the surface chemistry or NP shape on the resulting morphology is observed. Besides the composition control, morphology control of the NP-aerogels came into sight. Differing from the traditional building blocks of OD particles, colloidal NPs of nanorods, 1D nanowires, and 2D nanosheets have been employed as the building blocks to fabricate 3D porous aerogels. ${ }^{30,35-38}$ And their applications in catalysis, energy transfer/storage, and adsorbents have been explored. It is noted that aerogels originating from $2 \mathrm{D}$ graphene nanosheets have been excluded here because of the wealth of literature on this topic and it would deserve a special volume on this content.

\section{Function-led design of Aerogels}

The properties of NP-aerogels can benefit not only from the inherent nature of both aerogels and building blocks like ultra-low density, large surface area, high porosity, and catalytic, optical, conductive or electronic features, but also the improved or collective characteristics, which make them intensely studied objects in science and technology. Due to these unique properties, NP-aerogels are used for various applications including catalysis, sensing, optoelectronics, pollutants adsorbent/filtration, and beyond as discussed below.

\subsection{Aerogels as catalysts}

\subsubsection{Electrocatalysis}

Gels and aerogels derived from the 3D assembly of noble metal NPs combine the advantages of noble metals and aerogels, such as the metallic backbone (endows good conductivity), large surface area (provides more reactive surface and sites), high porosity (accelerates mass transfer), and self-supportability (eliminates support corrosion), which unleashed tremendous potential in electrocatalysis. Our group has pioneered the work on metal 


\section{Journal Name}

\section{ARTICLE}
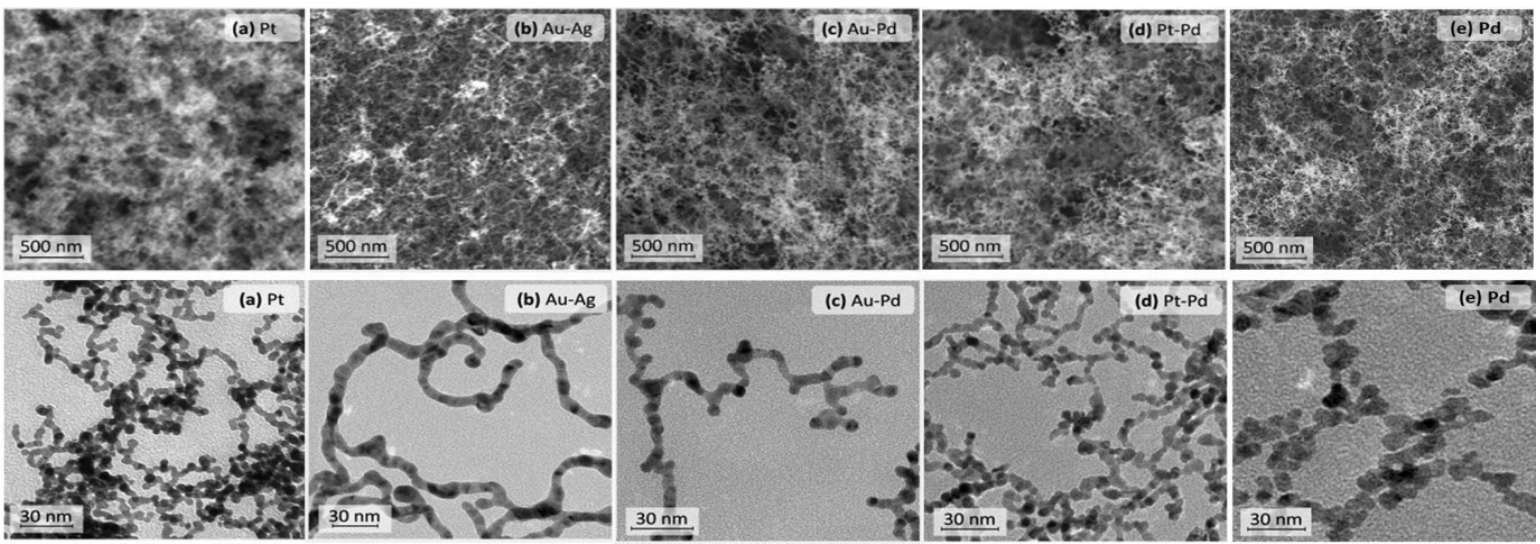

Figure 1. Scanning electron microscopy and transmission electron microscopy images of some representative mono- or multimetallic metal aerogels: (a) Pt, (b) Au-Ag, (c) Au-Pd, (d) Pt-Pd, and (e) Pd. ${ }^{39,40}$

aerogels as electrocatalysts in fuel cell reactions. ${ }^{11}$ We developed a spontaneous one-step gelation process, and prepared mono- or multimetallic aerogels of various compositions containing $\mathrm{Pt}, \mathrm{Pd}, \mathrm{Au}$ and Ag. ${ }^{19,39,40}$ These metallic aerogels have 3D nanowire or nanochain network-like morphologies with large specific surface areas (about $50-170 \mathrm{~m}^{2} \mathrm{~g}^{-1}$ ) and high porosities (the specific total pore volumes range from $1-542 \mathrm{~cm}^{3} \mathrm{~g}^{-1}$ ), as shown in Figure 1. Notably, the Pd aerogels capped with cyclodextrins and the PdPt bimetallic aerogels have shown excellent performance as electrocatalysts with both high catalytic activity and durability for alcohol oxidation and the oxygen reduction reaction (ORR), respectively, compared to commercial $\mathrm{Pd} / \mathrm{C}$ and $\mathrm{Pt} / \mathrm{C}$ catalysts. ${ }^{41,42}$

The outstanding performance of noble metal aerogels in the aforementioned electrocatalytic application stimulates great interest in enriching the diversity of the metallic aerogels. The wide commercialization of fuel cells requires developing electrocatalysts, taking into account their durability alongside their cost and activity. Recent efforts to integrate non-noble elements into noble metal nanomaterials have been proven as an efficient route. The introduction of external non-noble metals into noble metal aerogels can effectively reduce the cost of the catalyst, which is favorable for their commercialization on the one hand. On the other hand, the synergetic effects between the compositions will greatly enhance the activity and stability towards reduction/oxidation reactions. For example, a facile and general strategy for the kinetically controlled synthesis of a series of PdNi bimetallic porous aerogels in aqueous solution at room temperature was presented by our group. ${ }^{43}$

Because the 3D networks display very high surface areas and large porosities, the as-prepared PdNi exhibit greatly enhanced activity and stability towards methanol electrooxidation in an alkaline medium. On the basis of this convenient preparation, recently, Zhu et al. improved the approach for the creation of a series of MCu (M $=\mathrm{Pd}, \mathrm{Pt}$, and $\mathrm{Au}$ ) bimetallic aerogels from the one step in situ direct sol-gel methods, either via a two-step gelation process orv reduction of metal precursors with $\mathrm{NaBH}_{4}$ through speeding up the gelation kinetics in aqueous solution at elevated temperature (i.e., $\left.60{ }^{\circ} \mathrm{C}\right) .44$ The as-synthesized 3D porous $\mathrm{PdCu}$ with well-defined nanowire network and large-scale production, display excellent electrocatalytic performance toward ethanol electrooxidation with high activity in terms of a less positive anodic onset potential and high mass current density ( $3.472 \mathrm{~A} \mathrm{mg}_{\mathrm{Pd}}$ ), which ${ }^{-1}$ are also advantageous over those of Pd nanowire networks and Pd/C catalysts. In addition, the combination of $\mathrm{Pt}$ and $\mathrm{Ni}$ in bimetallic aerogels yields electrocatalysts with a mass-normalized ORR activity being about 2-fold higher than that of a commercial Pt/C catalyst and has reached the Department of Energy target for automotive polymer electrolyte fuel cells. 45

It is well-known that the properties of materials are mainly determined by their structures, while the applications of materials are largely determined by their properties. ${ }^{46} \mathrm{An}$ alternative strategy to enhance the electrocatalytic performance as well as to lower the price of electrocatalysts to meet the commercial requirements is manufacturing hollow structures of aerogels. This has been demonstrated in previous work by assembling hollow building blocks into gels or nanostructure engineering of as-prepared metal gels into hierarchical porous hollow structures like nanotubular frameworks, as displayed in Figure 2. As we know, one plausible approach to endow aerogels with specific properties while preserving their other attributes is to fine-tune thebuilding

blocks. Cai et al. reported on a new class of hierarchical aerogels electrocatalysts composed of multimetallic $\mathrm{PdNi}$ hollow nanospheres (PdNi NHS) or Ni-Pdx $\mathrm{Pt}_{\mathrm{y}}$ dendritic nanocrystals with continuously engineered shape and compositions. ${ }^{48,49}$ The combination of hollow building blocks and the 3D network structure, accompanied by transition metal doping, make these 
(A)
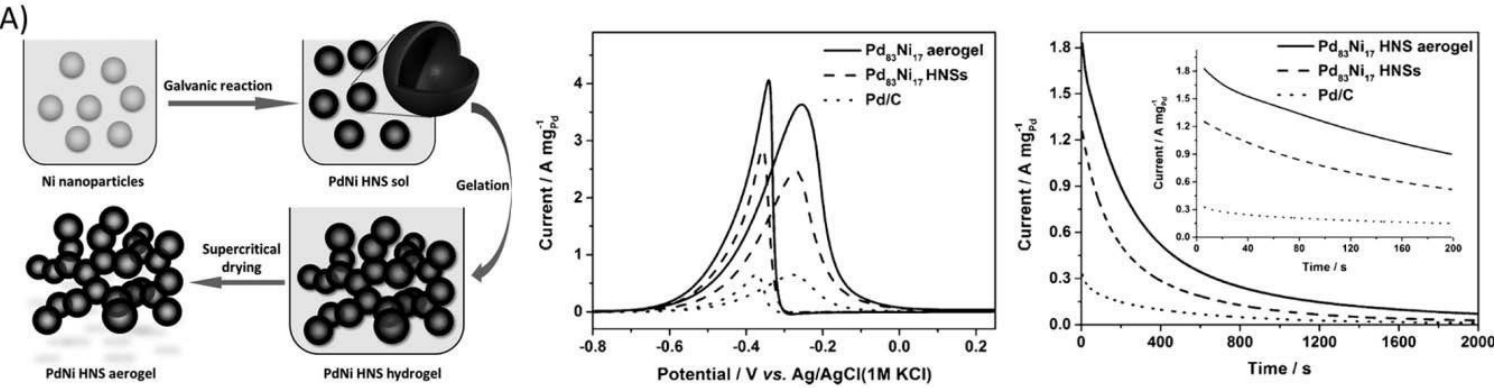

(B)
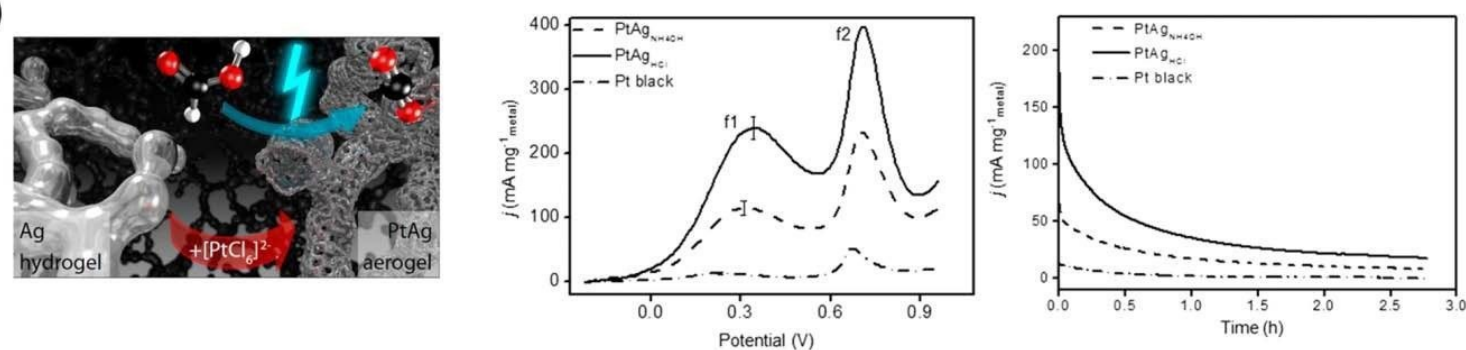

Figure 2. (A) Schematic illustration of the synthesis procedure for the $\mathrm{Pd}_{83} \mathrm{Ni}_{17} \mathrm{HNS}$ aerogel and its catalytic performance towards ethanol oxidation..$^{48}$ (B) Schematic illustration of the synthesis PtAg nanotubular aerogels and their catalytic performance towards formic acid oxidation. ${ }^{50}$

of the optimized ratio of $\mathrm{PdNi} \mathrm{HNS}$ aerogel and $\mathrm{Ni}-\mathrm{Pd}_{\mathrm{x}} \mathrm{Pt}_{\mathrm{y}}$ aerogel with catalytically beneficial morphologies are 5.6- and 10.6-fold higher than those of the commercial Pd/C catalyst, respectively. By taking advantage of nanostructure engineering, Liu et al. fabricated PtAg nanotubular aerogels (NTAGs) with high electrocatalytic activity and good durability via a simple galvanic replacement reaction between the in situ spontaneously gelated $\mathrm{Ag}$ hydrogel and the $\mathrm{Pt}$ precursor (i.e., $\mathrm{H}_{2} \mathrm{PtCl}_{6}$ ). ${ }^{50}$ Due to the unique structure of hierarchical porous network features, the PtAg NTAGs exhibit greatly enhanced electrocatalytic activity toward formic acid oxidation, reaching 19 times higher metal-based mass current density as compared to the commercial Pt black. Furthermore, the PtAg NTAGs show outstanding structural stability and electrochemical durability during the electrocatalysis.

In addition, NP-aerogels based on other compositions like oxides and carbon have been also used as electrocatalysts for the ORR for energy conversion/storage. For example, $\mathrm{MnO}_{2}$ ultrathin nanosheets were assembled into 3D nanoflower networks by a chemical reaction of manganese precursors in a waterdimethylformamide mixed solution, frozen by liquid nitrogen, and thawed in a freeze drier. The resulting material combined a number of excellent structural properties such as highly exposed active sites, rich porosity, and 3D continuous network. It is favorable for ORR/OER, and showed a higher discharge capacity than its counterparts without 3D architecture. The $\mathrm{Li}-\mathrm{O}_{2}$ cells with 3D $\mathrm{MnO}_{2}$ aerogel as the cathodic catalyst demonstrated good rate capability and cycling performance, which outperforms ( $4581 \mathrm{~mA} \mathrm{~h} \mathrm{~g}^{-1}$ ) those of many $\mathrm{MnO}_{2}$ and other transition metal-based electrocatalysts. ${ }^{51}$ In another report, "carbon nanoleaf" networks were constructed as aerogels with nitrogen-doped CNTs by a hydrothermal treatment, which possessed a large surface area (380-497 $\mathrm{m}^{2} \mathrm{~g}^{-1}$ ) and an excellent conductivity (up to $112 \mathrm{~S} \mathrm{~m}^{-1}$ ). The as-prepared 3D carbon nanoleaf architectures exhibited good electrocatalytic performance towards ORR with a positive onset potential $(0.03$ and $0.04 \mathrm{~V}$ vs. $\mathrm{Ag} / \mathrm{AgCl})$, ultra-low hydrogen peroxide production $(6.45 \%$ and $5.5 \%$ ), and excellent durability (approximately $88 \%$ of the relative current after working for $20000 \mathrm{~s}$ ). That is comparable to or better than those of commercial Pt/C catalysts both in alkaline and acidic solutions. ${ }^{52}$

\subsubsection{Photocatalysis}

Anatase titanium dioxide NPs are amongst the most prominent examples of nanosized photocatalysts. ${ }^{53}$ However, due to the high surface-to-volume ratio, the NPs tend to agglomerate, which would reduce the accessible surface area and reactive activity. Assembling $\mathrm{TiO}_{2}$ NPs into 3D open networks prevents their agglomeration to provide high surface area and excellent accessibility of the active surfaces on one hand. And on the other hand, it avoids the drawbacks of the amorphous nature and difficulties of synthesizing 


\section{Journal Name}

\section{ARTICLE}

(A)

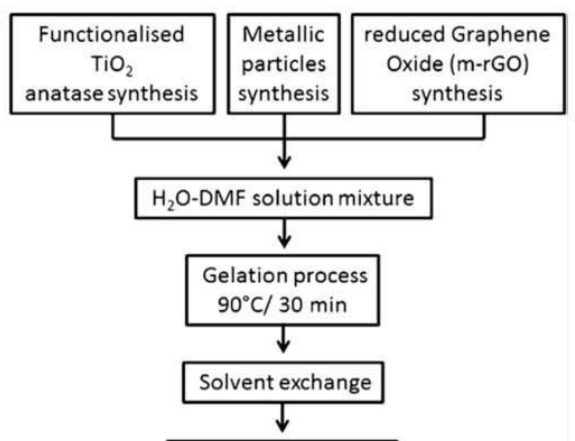

$\mathrm{CO}_{2}$ Supercritical dry (31 $1^{\circ} \mathrm{C} @ 74$ bar)

(B)

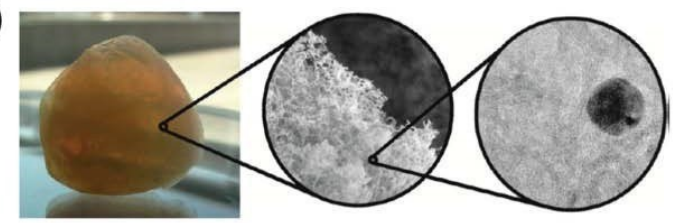

(C)
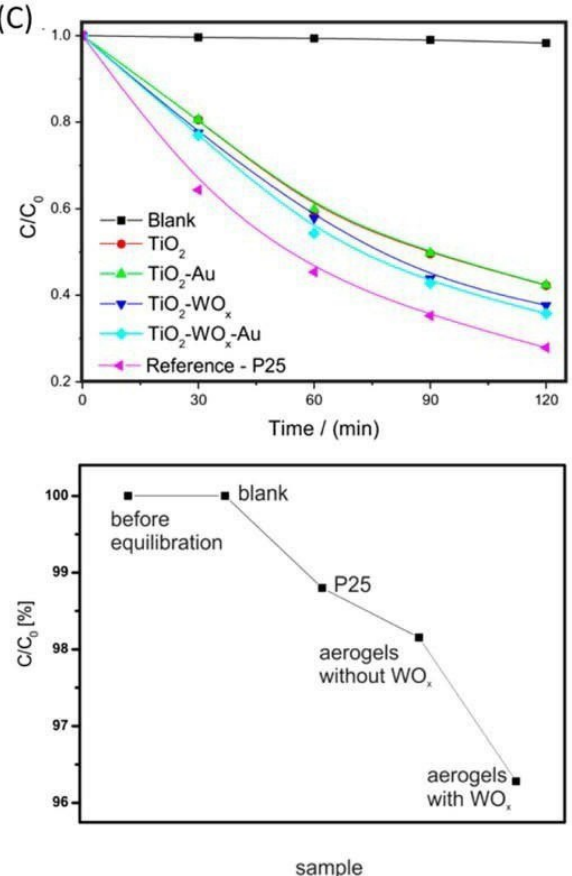

Figure 3. (A) Multicomponent aerogel preparation process. ${ }^{57}$ (B) photograph of a translucent monolith of a

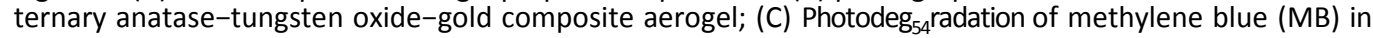
the presence of the different aerogels and the standard $\mathrm{TiO}_{2}$ material.

binary or ternary transition-metal-oxide based aerogels or composite aerogels consisting of different types of materials via traditional sol-gel routes.

The Niederberger group developed the co-assembly of anatase $\mathrm{TiO}_{2} \mathrm{NPs}$ with other metal/oxide nanostructures, leading to $\mathrm{TiO}_{2}$ composite aerogels with enhanced photocatalytic activities, as shown in Figure 3. Controlled by their surface functionalization, the preformed $\mathrm{TiO}_{2} \mathrm{NPs}$ underwent an oriented attachment process during gelation, fabricating a 3D macroporous network. The presence of other NPs in the initial reaction mixture resulted in the formation of multicomponent aerogels, offering a flexible tool to vary the composition of the gels and thus the chemical properties. For instance, they reported on a co-assembly of titania with Au NPs; the $\mathrm{Au}-\mathrm{TiO}_{2}$ composite aerogel showed enhanced activity towards the degradation of Rhodamine $B(\mathrm{RhB})$ under visible light. ${ }^{21} \mathrm{Here}$, a small particle size of the anatase $\mathrm{TiO}_{2}$ particles $(\sim 5.5 \mathrm{~nm})$ in the aerogel and the addition of $\mathrm{Au}$ NPs to the titania aerogel significantly accelerated the decomposition of $\mathrm{RhB}$. Later a ternary aerogel consisting of $\mathrm{Au}$ NPs and tungsten oxide nanowires embedded in an anatase $\mathrm{TiO}_{2}$ matrix was developed, which has a high surface area and large open pores with defined crystallinity. The photocatalytic properties of the aerogels were characterized by their capability of $\bullet \mathrm{OH}$ radical formation and methylene blue dye degradation under UV light. ${ }^{54}$ Each of these three components specifically contributed to the performance of the as-synthesized aerogel as a photocatalyst with the tungsten oxide nanowires providing enhanced adsorption of the target molecules, ${ }^{55}$ and the gold NPs increasing the lifetime of the electron-hole pairs produced during the photocatalytic process ${ }^{56}$. Furthermore, multicomponent aerogels were prepared from preformed crystalline $\mathrm{TiO}_{2}$ NPs, Pt NPs, as well as multilayer reduced graphene oxide (m-rGO) and were subsequently tested for photocatalytic $\mathrm{H}_{2}$ evolution. This architecture was responsible for the enhancement of the photocatalytic activity, which reached a maximum hydrogen production rate of $11.61 \mathrm{mmol} \mathrm{H}_{2} \mathrm{~g}^{-1} \mathrm{~h}^{-1}$ for the $\mathrm{TiO}_{2}$ aerogel with a content of $0.4 \mathrm{wt} \% \mathrm{Pt}$. This value is much higher than that of a $\mathrm{Pt} / \mathrm{TiO}_{2}$ reference powder with only about $3.28 \mathrm{mmol} \mathrm{Hgg} \mathrm{h}$.

Recently, a $\mathrm{Ag}$ doped $\mathrm{MnO}_{2}$ aerogel monolith, prepared by introducing a catalyzed hydrothermal nanowire growth, was reported. The obtained aerogel with nanowires as the building blocks were tested for their photocatalytic performance in degradation of organic water pollutants. No loss of the nanowires was observed during the repeated circulation process. Aside from the intrinsic properties of $\alpha-\mathrm{MnO}_{2}$ and the Ag NPs improving on the photocatalysis, the 3D continuous supermacropore system effectively eliminates the mass transport issue and the highly 
nanostructured $\mathrm{Ag}-\mathrm{MnO}_{2}$ aerogel provides large surface for photocatalytic reactions. ${ }^{58}$

\subsubsection{Gas phase heterogeneouscatalysis}

Generally, during the aforementioned electro- and photocatalytic tests in water, the monolithic body falls apart into pieces. Thus it would be very interesting to fully exploit the advantages of the monolithic structure of the aerogels from the 3D assembly of NPs, e.g., gas-phase reactions. Our group demonstrated a facile method to obtain a mixed $\mathrm{ZnPd} / \mathrm{ZnO}$ aerogels via a reductive treatment of a preformed $\mathrm{Pd} / \mathrm{ZnO}$ aerogel where different morphologies of the $\mathrm{Pd} / \mathrm{ZnO}$ aerogels could be achieved by controlling the destabilization of the $\mathrm{ZnO}$ sol. That is, gels with a sponge-like morphology could be obtained via a common oxidative destabilization of the sol using $\mathrm{H}_{2} \mathrm{O}_{2}$, while gels with a flake- and ribbon-like structure the polarity of the ethanolic ZnO NP suspension was increased by the addition of water (Figure 4). The Pd NPs were produced by an in situ reduction and subsequently deposited onto the pre-solvogel during the destabilization. All $\mathrm{ZnPd} / \mathrm{ZnO}$ aerogels show a high $\mathrm{CO}_{2}$ selectivity of up to $96 \%$ and a very good activity in methanol steam reforming that delivers hydrogen of $1540 \mathrm{mmol} \mathrm{H}_{2} /(\mathrm{mmol} \mathrm{Pd} \mathrm{h})$, which is one of the most important fuels for future energy concepts..$^{59}$ In addition, the catalytic properties of cryogelated noble metal aerogel monoliths of $\mathrm{Pt}$ and $\mathrm{Pd}$ were investigated in the room temperature $\mathrm{CO}$ conversion and spontaneous catalytic reactions. ${ }^{60}$ As there are only a few reports on aerogels as catalysts in gas-phase reactions, which employed an entirely monolithic structure of the aerogels, thus, further holds promise of their broader application incatalysis.
(A)

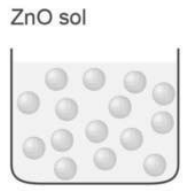

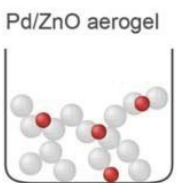

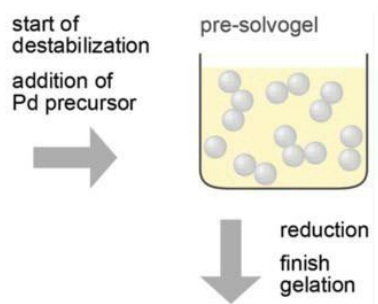

$\mathrm{Pd} / \mathrm{ZnO}$ solvogel

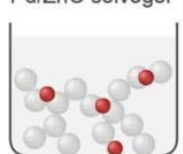

(B)

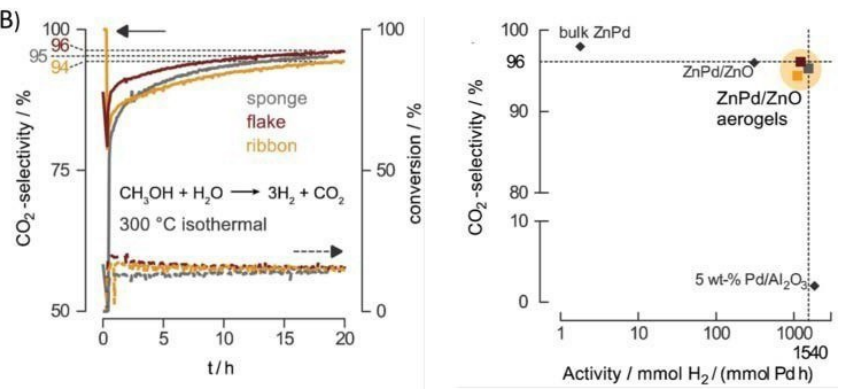

Figure 4. (A) Preparation scheme of mixed $\mathrm{Pd} / \mathrm{ZnO}$ aerogels. (B) Catalytic properties of the pretreated materials in for the methanol steam reforming reaction. ${ }^{59}$

\subsection{Aerogels insensing}

\subsubsection{QD-aerogels}

The optical properties of QDs make them ideal materials for ultrasensitive and multiplexing applications in optical sensing. Generally, fluorescence transduction is based on the principle that chemical/physical interactions occur at the surface of the QDs and change the efficiency of the radiative recombination, leading to either photoluminescence (PL) activation or quenching. ${ }^{61,62}$ Nowadays, sensing applications and devices benefit also from NP assemblies in the solid state instead of NPs in solutions. ${ }^{9,63}$ The 3D assembly of QDs as building blocks into functional simplify sensor fabrication and extend their applications to portable devices.

For the first time, Brock et al. exploited chalcogenide aerogels for optical sensing. The CdSe aerogels prepared via a partial oxidative removal of the surface thiolate groups of CdSe NPs exhibited a linear concentration-dependent $\mathrm{PL}$ intensity response to triethylamine. Compared to results from single NPs and NPpolymer composites, the CdSe aerogels showed a significant and reversible enhancement of the luminescence intensity upon exposure to triethylamine relative to the intensity under pure argon gas. This is probably due to the porous structure and the high surface to interior atom ratio of the aerogels allowing for good accessibility of gaseous analytes and maximizing the available binding sites on the nanoscale domains. The PL response was dependent on the concentration and it was linear in the range from $4.7 \times 10^{3}$ to $75 \times 10^{3} \mathrm{ppm}$ of triethylamine concentration. ${ }^{64}$

Because the pore sizes throughout the meso and macro regimes of QDs-based aerogels are appropriate for the encapsulation of a variety of biomolecules, QD gels also provide potential in the biosensor development. When encapsulating enzymes or other biomolecules, both biorecognition units (enzymes) and signalling units (QDs) are integrated in such a hybrid material. Our group developed an enzyme-encapsulating $\mathrm{CdTe} Q \mathrm{QD}$ gel as a multifunctional platform for biosensors. Specifically, by choosing a neutral phosphate buffer to dissolve the precipitated mercaptosuccinic acid-capped CdTe QDs, a sol-gel switching was also observed in the as-prepared QD gels. CdTe QD hydrogels encapsulating the tyrosinase were further manufactured and applied in the detection of dopamine (Figure 5). The CdTe gels provide a good matrix to encapsulate tyrosinase as "cage" without obvious structural changes and allow for relatively fast diffusion of substrate to the enzyme due to the large surface area and high porosity. With the quantum confinement effect and the high enzymatic activity well retained, the dopamine biosensor based on the enzyme-encapsulating CdTe QD hydrogel showed a detection limit of $50 \mathrm{nM}$ in a concentration range from $50 \mu \mathrm{M}$ to $1.0 \mathrm{mM}$. Furthermore, both hydrogels and xerogels exhibited a good sensing performance to the example analyte. As a versatile enzyme entrapment matrix, the QD gels offer great potential in the development of various enzyme-based biosensors and portable sensing devices. However, it should be pointed out that such biosensors would respond to a variety of phenolic compounds, which indicates that the poor selectivity remains to be resolved before practical 


\section{Journal Name}

\section{ARTICLE}

(A)

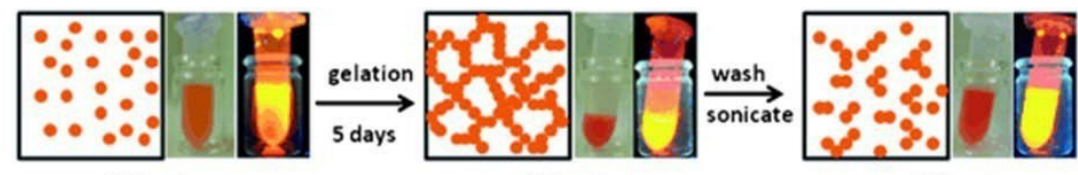

QD sol

QD gel

QD sol

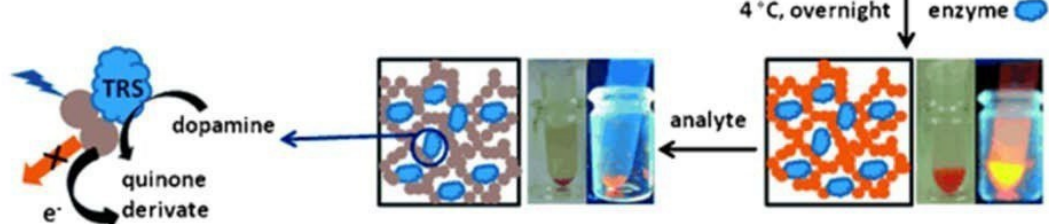

fluorescence quenching of $Q D$ gel by enzymatic product

enzyme-encapsulating QD gel

(B)

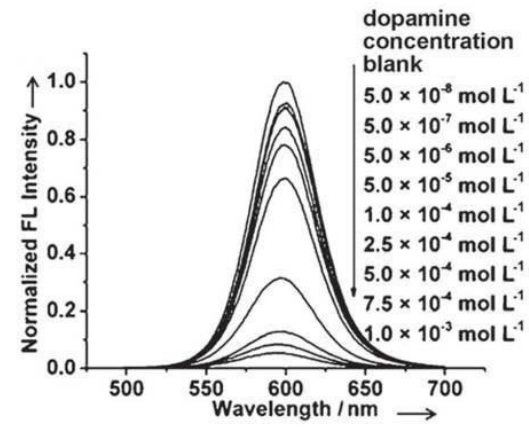

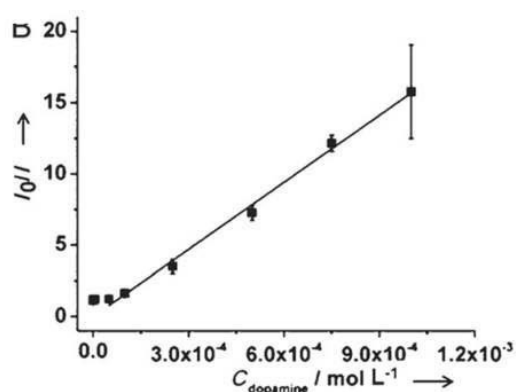

(C)
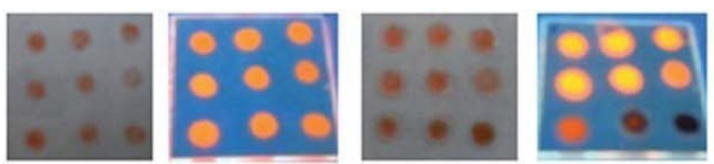

(A) Scheme of the encapsulation of enzymes in a QD gel using the sol-gel switching process of MSA-capped CdTe QDs and the sensing mechanism of the enzyme-QD hydrogel. Dopamine sensing based on the TRS-encapsulating CdTe QD hydrogel (B) and xerogel arrays (C). ${ }^{65}$

\subsubsection{Metal NPs}

Aside from the promising applications in catalysis, metal aerogels derived from NP assembly are also expected to provide a good matrix for biomolecules with high electrical conductivity, large surface area, and high porosity. In this respect, enzyme-loaded metal aerogels in combination with their meso/macroporous structure can facilitate electron and mass transfer processes, which are important for bioelectronic applications, e.g., as electrochemical biosensors. For example, glucose oxidase (GOD) was supported by different $\mathrm{Pd}$ aerogels to improve the glucose biosensing performance. Concentrated citrate-coated Pd NPs were induced to assemble with the aid of $\mathrm{Ca}^{2+}$ ions, where the growth of the $\mathrm{Pd}$ aerogels with different porosities and surface areas could be simply controlled by the addition of different concentrations of destabilizing agent. The current sensitivity of the optimal Pd aerogelbased enzyme electrode toward glucose in the range from 2 to 20 $\mathrm{mM}$ was estimated to be $1.11 \mu \mathrm{A} \mathrm{mM}^{-1}$, which was 125 and 3 times higher than those of glassy carbon and the original Pd NPs as enzyme supports, respectively. ${ }^{40}$ It is noted that the mediator, ferrocenecarboxylic acid $(\mathrm{Fc})$ was dispersed freely in the glucose solution, which will be an obstacle to develop integrated glucose sensing devices. Thus, a beta-cyclodextrin $(\beta-C D)$ modified $\mathrm{Pd}$ aerogel was functionalized with Fc via a host-guest interaction and subsequently produced a composite aerogel mediator for GOD for glucose oxidation. This integrated enzyme electrode could be used as both sensitive glucose biosensor and bioanode of membraneless glucose $/ \mathrm{O}_{2}$ biofuelcells. ${ }^{66}$ 


\section{Journal Name}

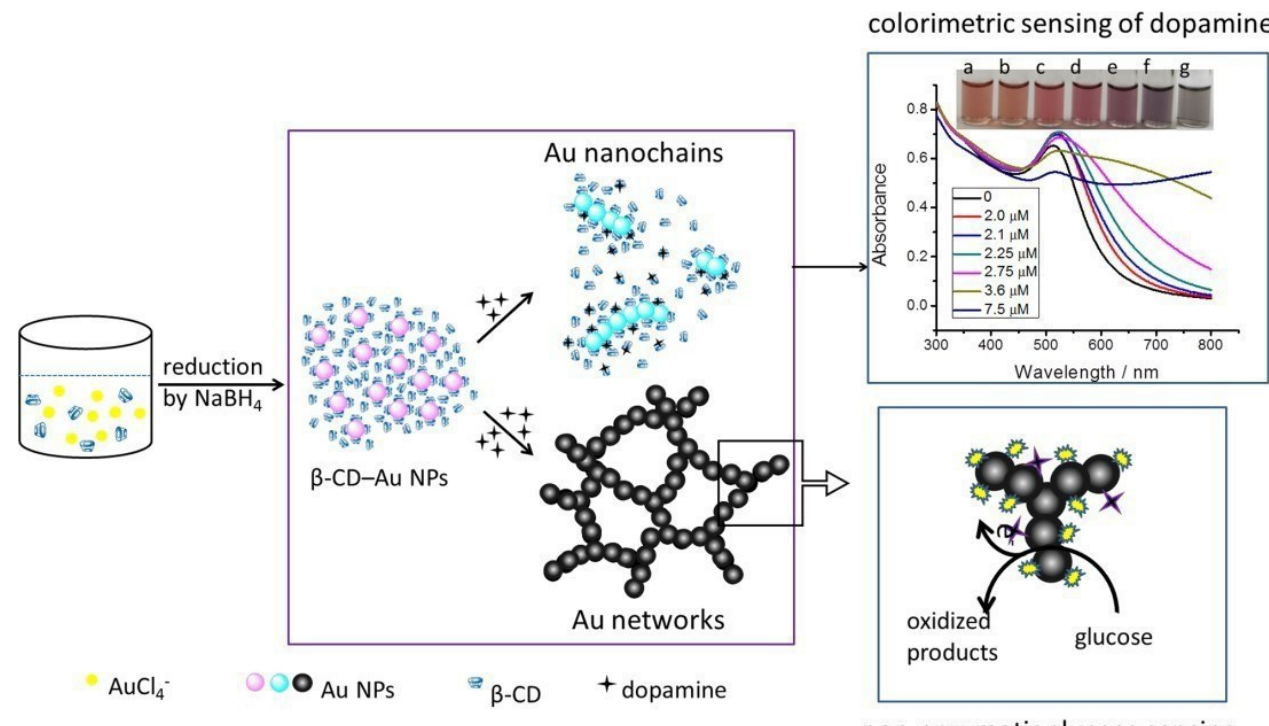

Figure 6. Schematic illustration of the colorimetric sensing of dopamine and the non-enzymatic glucose sensing based on the 3D assembly of cyclodextrin-modified Au NPs induced by dopamine. ${ }^{67,69}$

The utilization of Au NPs as colorimetric sensing platforms is gaining considerable attention due to the high extinction coefficients and the unique size dependent optical properties, which open access to high sensitivity with unsophisticated transducers. During the process of assembling Au NPs into gels, the structural change in terms of size and morphology endows the possibility to detect the destabilizing agents, when this assembly is concentrationdependent. Wen at al. demonstrated a facile colorimetric strategy for the determination of dopamine, where the natural $\beta-C D$ modified Au NPs ( $\beta-C D-A u$ NPs) were directly employed as optical probes ${ }^{67}$ The method relied on a controlled destabilization of the $\beta$ $\mathrm{CD}-\mathrm{Au}$ NPs and the growth of the Au assemblies (i.e., "peanutshaped," short chain, and wire-network nanostructures) by means of simply tuning the dopamine concentration, as illustrated in Figure 6. With the color change in the assembly process, the amount of the target is quantified, which enables a simple and sensitive detection of dopamine with a detection limit of $20 \mathrm{nM}$. Additionally, the optical sensor exhibited high selectivity for coexisting interferences as well as for analogues, carrying promise for a real sample test. It is interesting to note that the dopamineinduced 3D assembly of Au NPs is versatile and can be applied for surface engineering of $\mathrm{Au}$ aerogels. The as-prepared $\mathrm{Au}$ aerogels possess different functional groups (i.e., $\beta-C D$, citrate, and nonstabilizers (without organic surface ligands)) and all exhibit large surface areas and high porosity. Taking glucose and ethanol as examples, the electrochemical results showed that the catalytic progress was greatly promoted by the Auaerogelfunctionalized with $\beta-C D$ due to the advantages of noble metal aerogels and also probably a hos-t guest effect. ${ }^{68}$ This suggests that the Au aerogel exhibits high sensitivity, a broad linear range, and good stability, holding promise for the $A_{\beta}-C D / G C E$ as a nonenzymatic sensing electrode for analytical applications. ${ }^{69}$

\subsubsection{Anisotropic building blocks}

Recently, aerogels have started to be adopted as pressure sensors because of their good electrical conductivity, excellent mechanical properties, and ultralow density which can reduce the overall weight of electronic equipment.[70] A "bubble controlled assembly" of Cu NWs into hydrogel was proposed, and ultralight flexible pressure sensors with tunable sensitivities $\left(0.02 \mathrm{kPa}^{-1}\right.$ to 0.7 $\mathrm{kPa}^{-1}$ ) are fabricated from the obtained $\mathrm{Cu} \mathrm{NW}$ aerogels. This greatly broadens the application potential of the nanowire-based aerogels. $^{71}$

Furthermore, a tungsten oxide aerogel with a unique 3D network consisting of uniform ultrafine nanowires was fabricated by a polyethyleneimine-assisted hydrothermal method. Based on the direct electrochemistry of GOD on the $\mathrm{W}_{18} \mathrm{O}_{49}$ aerogel, the enzyme electrode with aerogel obtained at $\mathrm{pH}=3$ showed excellent sensing performance in terms of high sensitivity $\left(2.69 \times 10^{-4} \mathrm{~mA} \mathrm{mmol}{ }^{-1}\right.$ $\left.\mathrm{cm}^{-2}\right)$, low detection limit $(10 \mu \mathrm{M})$, and fast response $(10 \mathrm{~s})$ in the glucose determination. ${ }^{72}$

Wang at al. reported a porous $\mathrm{MoS}_{2}$ composite aerogel-supported Au NPs using graphene oxide - doped $\mathrm{MoS}_{2}$ sheets as the feedstock by hydrothermal assembly. Such composite aerogels not onlycan 
sensitively detect mercury(II) in aqueous solution by a colorimetric method with a low detection limit (3.279 nM) but also can exhibit a good mercury adsorption capacity $\left(\sim 1527 \mathrm{mg} \mathrm{g}^{-1}\right)$ and fast desorption ability. The excellent performance of the aerogel profits from its 3D interconnected macroporous framework as well as strong coupling between Au NPs and $\mathrm{MoS}_{2}$ nanosheets. ${ }^{73}$

\subsection{Optoelectronics}

Owing to their size- and shape-dependent optical and electronic properties, QD-based materials have been particularly attractive in optoelectronic device applications such as light emitting diodes, field-effect transistors, photodetectors, and solar cells. ${ }^{74-78}$ The effective utilization of QDs in these devices involves an assembly method for the QDs which plays an important role to determine the performance of the devices and requires a facile electronic communication between adjacent QDs while retaining quantum confinement. Thus, sol-gel methods have the potential to meet their requirements, where metal chalcogenide QDs were assembled into 3D networks in terms of gels, xerogels and aerogels. $8,14,15,79$

The $\mathrm{CdSe}(\mathrm{ZnS})$ core(shell) aerogels prepared from the assembly of the corresponding NPs into mesoporous colloidal networks showed a low resistance in the electrical transport $\left(\sim 10^{-3} \mathrm{~S} \mathrm{~cm}^{-1}\right)$ while maintaining quantum-confinement, which provides a pathway for the exploitation of $Q D$ gels in optoelectronic applications. ${ }^{80}$ When these $\mathrm{CdSe}(\mathrm{ZnS})$ aerogels were mixed with poly(3-hexylthiophene) (P3HT) and investigated by means of photoelectrochemistry and transient absorption spectroscopy, they showed increased photocurrents and charge generation in films containing lower loadings of inorganic material, in comparison to the organically capped, physically aggregated QDs. ${ }^{81}$ However, the first results on the fabrication of hybrid solar cells resulted in devices with poor performance. Further research on the investigation of the influence of annealing and purchasing smoother hybrid films (e.g., by incorporating the polymer in situ in the synthesis of the aerogels) would lead to improved performance. It is reported that the optoelectronic properties of QD films are limited by the poor interfacial chemistry and nonradiative recombinations due to surface traps. ${ }^{82}$ To address these performance issues, the solgel assembly of QDs was applied to fabricate thin films of CdSe and core(shell) CdSe(ZnS) QDs via a similar oxidative treatment, where connectivity was achieved by the formation of dichalcogenide covalent linkage between particles. The process of mild thermal annealing further enhanced the interparticle coupling, resulting in QD thin films with superior charge transport properties, as revealed by a more than 2 -fold enhancement in photocurrent

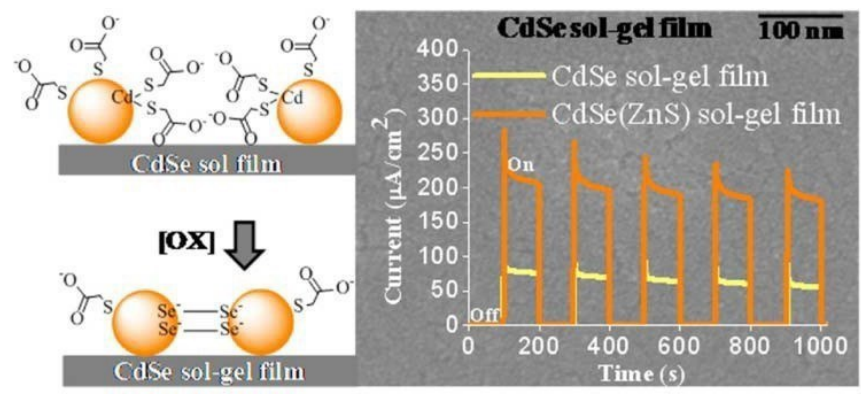

Figure 7. Mechanism of oxidative ([OX]) gelation of a thioglycolic acid-capped QD film (sol film) and photocurrent response of an annealed CdSe and CdSe(ZnS) sol-gel films. ${ }^{82}$ and a further increase in photovoltage with a thin $\mathrm{ZnS}$ shell, as shown in Figure 7.

Interlinking of metal NPs into 3D networks of QD-aerogels enables various processes like charge transfer and photoluminescence (PL) quenching and/or enhancement, which influence the optical properties of the designed materials. ${ }^{83-85}$ This kind of hybrid materials composed of metal and semiconductor components exhibit altered properties in comparison to their individual counterparts, imposing great interest for optoelectronic applications. Arachchige and co-workers reported on the synthesis of $\mathrm{CdSe} / \mathrm{Ag}$ nanoheterostructures (aerogels) via oxidation induced self-assembly of thiol-coated NPs and the evolution of optical properties as a function of composition. ${ }^{85} \mathrm{~A}$ new hybrid emission maximum was detected at $630-640 \mathrm{~nm}$ with a low Ag incorporation (0.27\%) and minimal changes to the absorption, whereas progressive red shifts and tailing effects in absorption onsets were noted at higher Ag loadings (0.53-1.83\%). The PL decays of the hybrid emission ( $600 \mathrm{~ns}$ ) are significantly different from those of the band-edge $(1.83 \pm 0.03 \mathrm{~ns})$ and trap-state $(1190 \pm 120 \mathrm{~ns})$ emissions of CdSe aerogels, suggesting the generation of an alternate radiative decay pathways.

\subsection{Adsorbents andfilters}

Mankind benefits in many ways from the worldwide industrial development but this also brings problems such as the increasing environmental deterioration from heavy metals, gaseous toxicants, and other pollutants that accompany industrial processes. ${ }^{86}$ Due to their inherent characteristics of high porosity, large surface area and unique chemical properties depending on the nature of the building blocks, the NP-based aerogels can be used as adsorbents/filters in water treatment and the removal of pollutants.

For example, the cation exchange reactions between $\mathrm{ZnS}$ aerogels and divalent cations (i.e., $\mathrm{Pb}^{2+}, \mathrm{Cd}^{2+}$ and $\mathrm{Hg}^{2+}$ ) occurred directly under very mild reaction conditions. ${ }^{87}$ Note that the presence of both, an accessible pore structure and exposed NP surfaces, is paramount for the promotion of the reaction, where most of the removal occurs through chemisorption to the accessible surface. A quantitative study revealed that the $\mathrm{ZnS}$ aerogel shows the highest capacity reported to date $\left(14.2 \mathrm{mM} \mathrm{g}^{-1}\right)$ for the removal of $\mathrm{Pb}^{2+}$ from aqueous solutions, superior to the reported oxidic and even layered sulfide materials. ${ }^{88}$ Another work is related to hydrogels/aerogels obtained from an insitu hydrothermal synthesis of $1 \mathrm{D}$ nanowires that directly form a cross-linked network during the synthesis process. ${ }^{29}$ The as-grown hydrogels can be used directly as water filters to remove pollutants such as heavy metal ions and toxic organic contents, as shown in Figure 8. The nanowire hydrogel filters exhibited an efficient performance to remove heavy metal ions; with $1 \mathrm{~mL}$ volume of the solution, the initial uptake for $\mathrm{Pb}^{2+}, \mathrm{Cd}^{2+}, \mathrm{Cr}_{2} \mathrm{O}_{7}^{2-}$, or $\mathrm{Cu}^{2+}$ was found to be $100,91,95$, and $88.3 \%$, respectively, and the uptake only decreased to $78,70,75,59 \%$, respectively with $15 \mathrm{~mL}$ of volume. ${ }^{89}$ Additionally, methylene blue $(\mathrm{MB})$ can be removed completely from the water through the nanowire hydrogel filter, as revealed from the UV-vis spectrum (cf. Fig. 8 (B) a). 


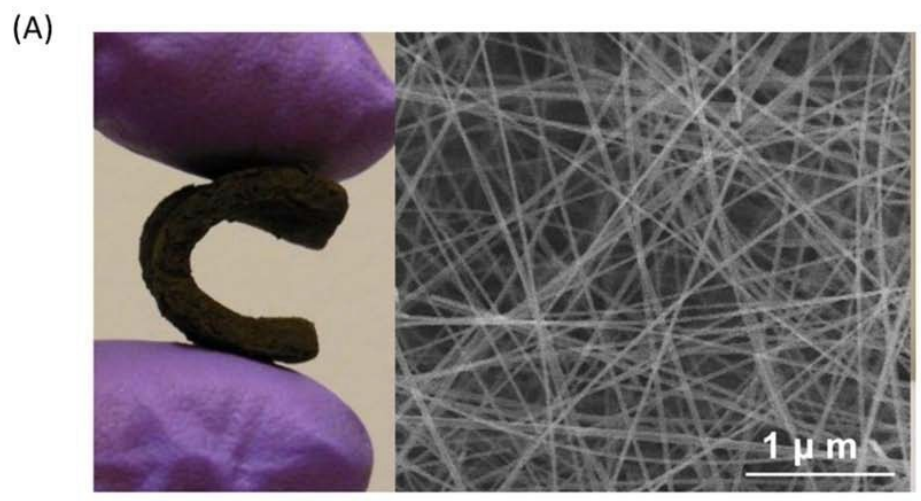

(B)
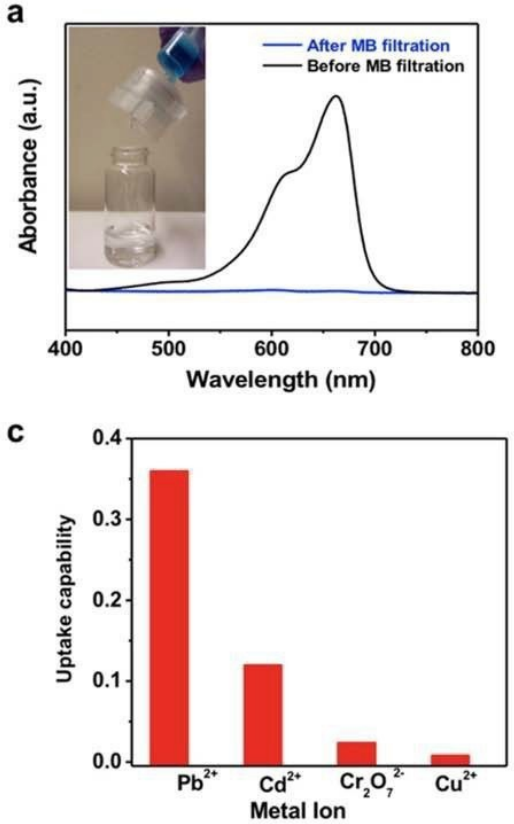

b

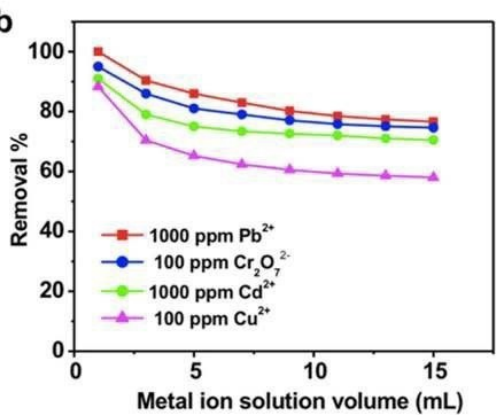

d

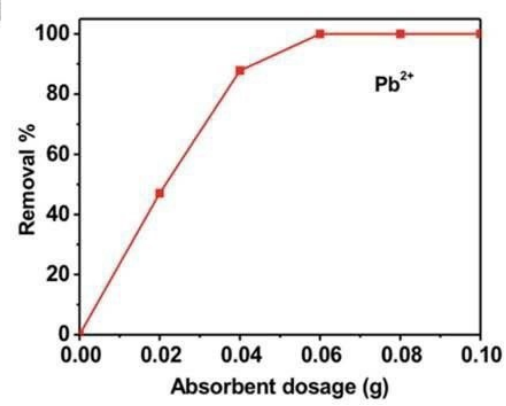

Figure 8. (A) Morphology of the cryptomelane nanowire aerogel and (B) water purification filters of the cryptomelane nanowire hydrogel for the removal of organic dyes (a) and toxic heavy metal ions (b-d). ${ }^{89}$

Porous materials with large surface areas have been successfully utilized for dye removal from contaminated water. ${ }^{90,91}$ Starting from crystalline $\mathrm{Y}_{2} \mathrm{O}_{3}$ nanosheets of about 1.5-2.0 nm thickness, nanosheet gels have been developed by a centrifugation-induced gelation process with tunable shape. The as-prepared $\mathrm{Y}_{2} \mathrm{O}_{3}$ gels were found to have a high capability to remove organic dyes such as $\mathrm{MB}$, methyl orange (MO), and congo red $(C R)$ from water. The maximum adsorption capacities were determined to be 8080,1166 , and $380 \mathrm{mg} \mathrm{g}^{-1}$ for $\mathrm{MB}, \mathrm{MO}$, and $\mathrm{CR}$, respectively. The authors assumed that hydrogen bonding is the main driving force for the adsorption of these dye molecules on the nanosheets, explaining the good adsorption of $\mathrm{MB}$ with its three sulfonate groups. ${ }^{92} \mathrm{MnO}_{2}$ is known for its oxidation ability and can be used as an adsorbent for reducing toxicants. ${ }^{93}$ The assembly of monodispersed organic-free $2 \mathrm{D} \mathrm{MnO}_{2}$ nanosheets into a high-purity inorganic aerogel via ice-templating was reported and used as an effective adsorbent for the toxic reducing gas, $\mathrm{N}_{2} \mathrm{H}_{4}$. Owing to its strong oxidation ability and highporosity, the obtained $\mathrm{MnO}_{2}$ aerogel exhibited superior absorption efficiency over $\mathrm{MnO}_{2}$ powders and are, thus, better candidates for applications in reducing gas absorption. ${ }^{94}$

\subsection{Some applications beyond}

In addition to the aforementioned applications, some very interesting and promising applications of NP-based aerogels have also been explored.

An example of recent work involves self-supported Au/Ag alloy aerogels prepared via the oxidative removal of surfactant ligands from $\mathrm{Au} / \mathrm{Ag}$ alloy NPs, which have been studied in surfaceenhanced Raman scattering (SERS) with Rhodamine 101 as the probe molecule. The alloy aerogels exhibited SERS signal intensities that are 10-42 times higher than those achieved from the original $\mathrm{Au} / \mathrm{Ag}$ alloy NPs. The Au/Ag alloy aerogel (molar ratio of $\mathrm{Au} / \mathrm{Ag}=0.72$ ) exhibited SERS sensing capabilities down to the 1 $\mathrm{nM}$ level. The signal increase obtained are probably attributed to the highly porous gel morphology and to the enhanced surface 


\section{Journal Name}

\section{ARTICLE}

(A)

(a)
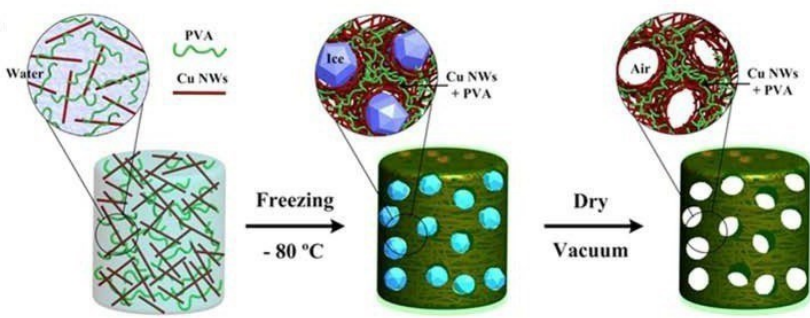

(b)
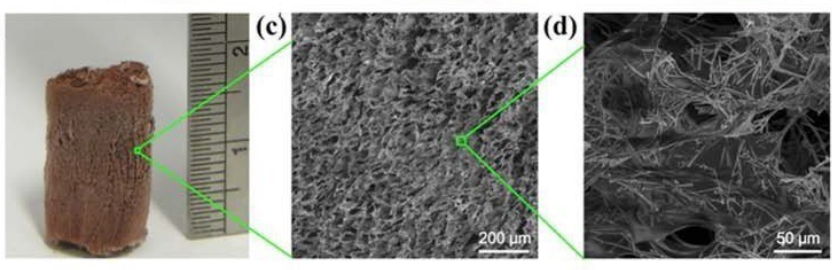

(B)

(a)
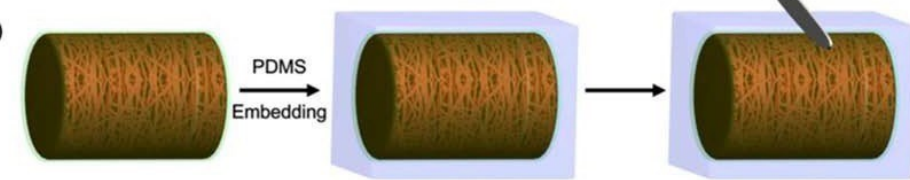

(b)

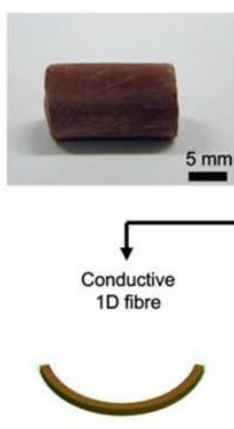

(c)

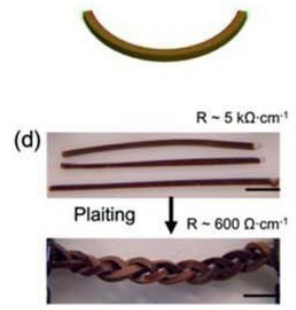

$(e)$
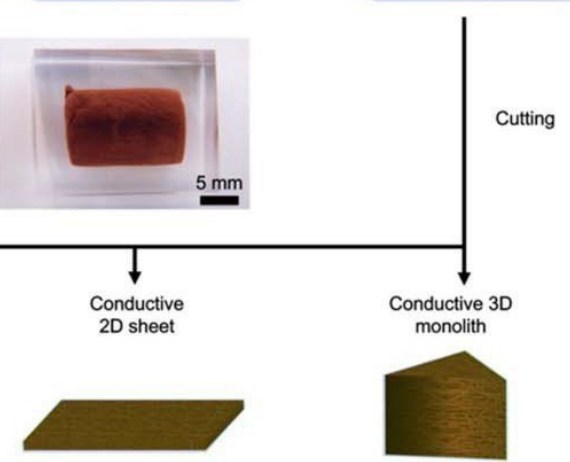

(e)
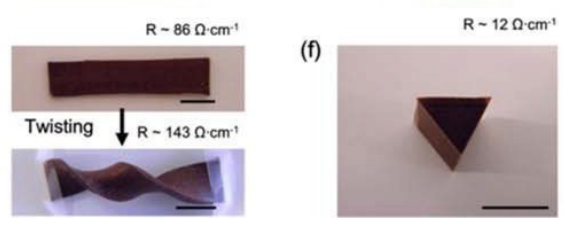

Figure 9. (A) Large-scale fabrication of CuNW-PVA composite aerogel monoliths: synthesis (a) process and morphologies (b-d). (B) Figure 5. Manufacturability of the conducting rubber ambers by simple knife cutting. ${ }^{97}$

roughness that can potentially generate a large number of plasmonic hot spots, creating efficient SERS substrates for future applications. ${ }^{95}$

As mentioned in Section 2, a porous bulk 3D copper nanowire (CuNW) aerogel formed as an interconnected CuNW hydrogel network during the in situ nanowire synthesis. Superior properties such as high porosity, high electrical conductivity, mechanical robustness, and excellent water wicking efficiency allow these "aerosponges" to be used in heat exchange with excellent performance. The CuNW aerosponge samples exhibited superior wicking behavior as compared to the sintered sample. The permeabilities of the wick are $2 \times 10^{-11} \mathrm{~m}^{2}\left(4.5 \mathrm{mg} \mathrm{cm}^{-3} \mathrm{Cu}\right.$ aerosponge) and $7 \times 10^{-12} \mathrm{~m}^{2}$ (5.76 $\mathrm{mg} \mathrm{cm}^{-3} \mathrm{Cu}$ aerosponge), which are comparable to or higher than previously reported values for 
sintered wicks in the literature of $10^{-13}-10^{-11} \mathrm{~m}^{2}$ and much higher than the permeability of the experimentally fabricated sintered wick sample of $2 \times 10^{-13} \mathrm{~m}^{2}$. These results suggest to use CuNW aerosponges in many liquid transport and thermal management applications like heat pipes with reduction in materials required for heat pipe wick fabrication (CuNW aerosponges use as little as $0.1 \%$ of the copper required for sintered wicks) while maintaining liquid supply and therefore device cooling as indicated by the wickingperformance. ${ }^{96}$

Remarkably, Cheng and co-workers produced ultralow-density $\mathrm{Cu}$ aerogel monoliths with well-defined shapes from 1D building blocks, Cu NWs, based on a freeze-casting method under mild conditions. ${ }^{31} \mathrm{~A}$ trace amount of additive, poly(vinyl alcohol) (PVA) could substantially improve the mechanical strength of the $\mathrm{Cu} N W$ aerogels while maintaining high conductivity $\left(\sim 0.83 \mathrm{~S} \mathrm{~cm}^{-1}\right)$ and ultralow density $\left(\sim 10 \mathrm{mg} \mathrm{cm}^{-3}\right) .{ }^{97}$ The Cu NW-PVA aerogels could be embedded into PDMS resin, forming conductive rubber ambers. The ambers could be further manufactured simply by cutting into any arbitrary 1D, 2D, and 3D shapes, which were all intrinsically conductive without the need of external prewiring, a condition required in the previous aerogel-based conductors (Figure 9). The outstanding electrical conductivity in conjunction with high mechanical compliance enabled prototypes of elastic piezoresistivity switches and stretchable conductors.

All the cut-shaped rubbers were conductive. The scale bar in Fig. 9 (B) $d-f$ is $1 \mathrm{~cm}$. As a new type of nanostructured material, aerogels could increase the efficiency of thermoelectric (TE) materials by controlling particle size and composition and by reducing the thermal conductivity. ${ }^{98}$ The Brock group has developed a series of QD-aerogels and explored their application as TE materials. ${ }^{99,100}$ Specifically, they produced Bi Te aerogels

with controlled microstructure and thermal conductivities to increase the TE figure of merit, yielding impressive power factor values $\left(6.06 \times 10^{-4} \mathrm{~W} \mathrm{~m} \mathrm{~m}^{-1} \cdot \mathrm{K}^{-2}\right)$. $^{101}$ Later the measurements of thermoelectric properties of $\mathrm{Bi}_{2} \mathrm{Te}_{3}$ and $\mathrm{Bi}_{x} \mathrm{Sb}_{2-\mathrm{x}} \mathrm{Te}_{3}$ aerogels were performed. Unfortunately, the as-prepared aerogels have inferior electronic properties compared to the respective NPs and bulk materials, leading to a poor power factor. ${ }^{102}$ Another kind of aerogel material, namely $\mathrm{PbTe}$ was probed and observed to sublime at a higher temperature and over a larger range (425-500 $\left.{ }^{\circ} \mathrm{C}\right)$ compared to the pure NPs. The good thermal stability combined with the presence of nanoscale interfaces suggests that $\mathrm{PbTe}$ gels may show promise in thermoelectric devices. ${ }^{98}$ Further advanced design of PbTe aerogel based TE materials through the incorporation of $\mathrm{PbS}$ inclusions or ligand stripping from the nanosized building blocks could offer possibilities of increasing the efficiency with an improvement of their electrical conductivity. ${ }^{99}$ Overall speaking, the high-efficiency in terms of a high value for the figure of merit of TE materials from QD-aerogels is still lacking; it is highly desirable yet challenging to achieve simultaneously a high electrical conductivity, a high thermopower, and a low thermal conductivity in onematerial.
Aerogels from NP building blocks carry the advantages of the traditional aerogels like ultralow density, high surface area and large pore volume, but also retain some of the unique properties of the NPs such as catalytic, optical, and electronic properties from their nano-scale size. Nowadays, the research interest of developing new synthetic strategies is still ongoing, however, aerogels have now reached a stage where the focus is on their applications. In this review, we summarize the function-led design of aerogels composed of OD spherical particles (Metal NPs, QDs, and oxide NPs), 1D nanowires ( $\mathrm{Ag}, \mathrm{Cu}$, etc), and 2D nanosheets $\left(\mathrm{MoS}_{2}, \mathrm{MnO}_{2}\right.$, etc), and their applications in catalysis, sensing, optoelectronics, pollutants adsorbents/filters, and beyond (SERS, heat dissipation, stretchable conductors, thermoelectronics, etc.). Despite the long history of aerogels, the development of selfsupported aerogels from NP building blocks and especially their applications are still in an early stage. Recent research revealed that the aerogels fabricated from the 3D assembly of colloidal NPs showed highly efficient catalysis, sensitive sensing, great potentials for optoelectronic applications, and high capability of pollutant absorbance orfiltration.

The design of aerogels towards task-specific superstructures is of great interest and importance. However, a number of challenges remain before the widespread implementation of these materials in various practical areas can be realized. Several critical issues regarding the morphology, composition, pore structure, and surface functionalities of these 3D porous nanostructures have been addressed. First, the structural engineering of the original building blocks and the final gels, either or both, would be an efficient way to increase the surface area, the number of active sites, and material utilization efficiency. Furthermore, the expansion of the types of the building blocks to broaden the scope from the initial OD spherical NPs to other low-dimensional NPs makes such aerogels much more versatile. Secondly, additional aerogel components will increase their functionalities due to multicompositional synergetic effects. Thirdly, the optimization of the pore structure, including the pore sizes, pore distributions, and porosities are critical issues for their specific applications. For example, the balance between micropores (contributing to the surface area to a large extent but limiting mass transport) and macropores (opposite to micropores) in 3D aerogels is believed to provide high surface area and concurrently allow for efficient mass transport, which are important features for their applications in catalysis, sensing, and as adsorbents. Fourthly, the surface functionalities of the aerogels are closely related to the activity in various applications. Surface engineering of the building blocks (e.g., defects, ligands) and developing proper gelation strategies will optimize the surface properties of the resulting aerogels for the desired applications. Research efforts along these lines, together with the unravelling of the gelation mechanisms are expected to contribute to the advancement in research and application of NP-basedaerogels.

\section{Conclusion and outlook}




\section{Acknowledgements}

This work is supported by the AEROCAT project (ERC-2013AdG 340419) and the DFG project EY16/18-1.

\section{References}

1 H. D. Gesser amd P. C. Goswami, Chem. Rev., 1989, 89, 765.

2 J. L. Gurav, I. K. Jung, H. H. Park, E. S. Kang and D. Y. Nadargi, J Nanomater., 2010,409310.

3 S. Kistler, Nature 1931, 127, 741.

4 N. Hüsing, and U. Schubert, Angew. Chem., Int. Ed.,1998, 37, 22.

5 F. Rechberger and M. Niederberger, Nanoscale Horiz., 2017, 2, 6 .

6 C. Ziegler, A. Wolf, W. Liu, A.-K. Herrmann, N. Gaponik and A. Eychmüller, Angew. Chem. Int. Ed., 10.1002/anie.201611552

7 J. L. Mohanan and S. L. Brock, J. Non-Cryst. Solids, 2004, $350,1$.

8 J. L. Mohanan, I. U. Arachchige and S. L. Brock, Science, 2005, 307, 397.

9 I. U. Arachchige and S. L. Brock, Acc. Chem. Res., 2007, 40, 801.

10 A. Hitihami-Mudiyanselage, K. Senevirathne and S. L. Brock, ACS Nano, 2013, 7, 1163

11 W. Liu, A. K. Herrmann, N. C. Bigall, P. Rodriguez, D. Wen, M. Oezaslan, T. J. Schmidt, N. Gaponik and A. Eychmüller, Acc. Chem. Res., 2015, 48, 154.

12 R. Deshmukh, E. Tervoort, J. Käch, F. Rechberger and M. Niederberger, Dalton Trans., 2016, 45, 11616.

13 L. Chen, C. Y. Xu, R. Du, Y. Y. Mao, C. Xue, L. M. Chen, L. T. Qu, J. Zhang and T. Yi, J. Mater. Chem. A, 2015, 3, 5617.

14 I. U. Arachchige and S. L. Brock, J. Am. Chem. Soc., 2006, 128, 7964.

15 I. U. Arachchige and S. L. Brock, J. Am. Chem. Soc., 2007, 129, 1840.

16 A. Wolf, V. Lesnyak, N. Gaponik and A. Eychmüller, J. Phys. Chem. Lett., 2012, 3, 2188

17 Q. Yao, I. U. Arachchige and S. L. Brock, J. Am. Chem. Soc., 2009, 131, 2800.

18 G. S. Armatas and M. G. Kanatzidis, Nat. Mater., 2009, 8, 217.

19 N. C. Bigall, A.-K. Herrmann, M. Vogel, M. Rose, P. Simon, W. Carrillo-Cabrera, D. Dorfs, S. Kaskel, N. Gaponik and A. Eychmüller, Angew. Chem. Int. Ed., 2009, 48, 9731.

20 J. Schroers, C. Veazey and W. L. Johnson, Appl. Phys. Lett., 2003, 82, 370.

21 F. J. Heiligtag, M. D. Rossell, M. J. Süess and M. Niederberger, J. Mater. Chem., 2011, 21, 16893.

22 F. J. Heiligtag, N. Kränzlin, M. J. Süess and M. Niederberger, J Sol-Gel Sci. Technol., 2014, 70, 300.

23 N. Gaponik, A.-K. Herrmann and A. Eychmüller, J. Phys. Chem. Lett., 2012, 3, 8.

24 Michel A. Aegerter, N. Leventis and M. Koebel, Aerogels Handbook, Springer, 2011, pp 367.

25 X. N. Gao, R. J. Esteves, T. T. H. Luong, R. Jaini and I. U. Arachchige, J. Am. Chem. Soc., 2014, 136, 7993.

26 V. Lesnyak, S. V. Voitekhovich, P. N. Gaponik, N. Gaponik and A. Eychmüller, ACS Nano, 2010, 4, 4090.

27 S. V. Voitekhovich, V. Lesnyak, N. Gaponik and A. Eychmüller, Small, 2015, 11, 5728.

28 A. Wolf, V. Lesnyak, N. Gaponik and A. Eychmüller, J. Phys. Chem. Lett., 2012, 3, 2188.

29 P. H. Tewari, A. J. Hunt and K. D. Lofftus, Mater. Lett., 1985, 3, 363.
30 S. M. Jung, H. Y. Jung, M. S. Dresselhaus, Y. J. Jung and J. Kong, Sci. Rep. 2012, 2,849.

31 Y. Tang, K. L. Yeo, Y. Chen, L. W. Yap, W. Xiong and W. L. Cheng, J. Mater. Chem. A, 2013, 1,6723.

32 S. Chen, G. X. Liu, H. Yadegari, H. H. Wang and S. Z. Qiao, J. Mater. Chem. A, 2015, 3,2559.

33 H. L. Gao, L. Xu, F. Long, Z. Pan, Y. X. Du, Y. Lu, J. Ge and S. H. Yu, Angew. Chem., Int. Ed., 2014, 53,4561.

34 A. Freytag, S. Sánchez-Paradinas, S. Naskar, N. Wendt, M. Colombo, G. Pugliese, J. Poppe, C. Demirci, I. Kretschmer, D. W. Bahnemann, P. Behrens and N. C. Bigall, Angew. Chem. Int. Ed., 2016, 55, 1200.

35 S. Bhanushali, P. Ghosh, A. Ganesh and W. L. Cheng, Small, 2015, 11, 1232.

36 S. Sánchez-Paradinas, D. Dorfs, S. Friebe, A. Freytag, A. Wolf and N. C. Bigall, Adv. Mater., 2015, 27,6152.

37 S. Naskar, J. F. Miethe, S. Sánchez-Paradinas, N. Schmidt, K. Kanthasamy, P. Behrens, H. Pfnür and N. C. Bigall, Chem. Mater., 2016, 28, 2089.

38 V. Sayevich, B. Cai, A. Benad, D. Haubold, L. Sonntag, N. Gaponik, V. Lesnyak and A. Eychmüller, Angew. Chem. Int. Ed., 2016, 55, 6334 .

39 A.-K. Herrmann, P. Formanek, L. Borchardt, M. Klose, L. Giebeler, J. Eckert, S. Kaskel, N. Gaponik and A. Eychmüller, Chem. Mater., 2014, 26, 1074.

40 D. Wen, A.-K. Herrmann, L. Borchardt, F. Simon, W. Liu, S. Kaskel and A. Eychmüller, J. Am. Chem. Soc., 2014, 136, 2727.

41 W. Liu, A.-K. Herrmann, D. Geiger, L. Borchardt, F. Simon, S. Kaskel, N. Gaponik and A. Eychmüller, Angew. Chem., Int. Ed., 2012, 51, 5743.

42 W. Liu, P. Rodriguez, L. Borchardt, A. Foelske, J. Yuan, A. K. Herrmann, D. Geiger, Z. Zheng, S. Kaskel, N. Gaponik, R. Kotz, T. J. Schmidt and A. Eychmüller, Angew. Chem. Int. Ed., 2013, 52, 9849.

43 C. Z. Zhu, D. Wen, M. Oschatz, M. Holzschuh, W. Liu, A.-K. Herrmann, F. Simon, S. Kaskel and A. Eychmüller, Small, 2015, 11, 1430.

44 C. Z. Zhu, Q. R. Shi, S. F. Fu, J. H. Song, H. B. Xia, D. Du and Y. H. Lin, Adv. Mater., 2016, 28, 8779.

45 S. Henning, L. Kühn, J. Herranz, J. Durst, T. Binninger, M. Nachtegaal, M. Werheid, W. Liu, M. Adam, S. Kaskel, A. Eychmüller and T. J. Schmidt, J. Electrochem. Soc., 2016, $163,998$.

46 X. J. Wang, J. Feng, Y. C. Bai, Q. Zhang and Y. D. Yin, Chem. Rev., 2016, 116, 10983.

47 K. G. S. Ranmohotti, X. N. Gao and I. U. Arachchige, Chem. Mater., 2013, 25, 3528.

48 B. Cai, D. Wen, W. Liu, A.-K. Herrmann, A. Benad and A. Eychmüller, Angew. Chem. Int. Ed., 2015, 54, 13101.

49 B. Cai, A. Dianat, R. Hübner, W. Liu, D. Wen, A. Benad, L. Sonntag, T. Gemming, G. Cuniberti and A. Eychmüller, DOI: 10.1002/adma.201605254.

50 W. Liu, D. Haubold, B. Rutkowski, M. Oschatz, R. Hübner, M. Werheid, C. Ziegler, L. Sonntag, S. H. Liu, Z. K. Zheng, A.-K. Herrmann, D. Geiger, B. Terlan, T. Gemming, L. Borchardt, S. Kaskel, A. Czyrska-Filemonowicz and A. Eychmüller, Chem. Mater., 2016, 28, 6477.

51 S. Chen, G. X. Liu, H. Yadegari, H. H. Wang and S. Z. Qiao, J. Mater. Chem. A, 2015, 3, 2559.

52 L. Chen, C. Y. Xu, R. Du, Y. Y. Mao, C. Xue, L. M. Chen, L. T. Qu, J. Zhang and T. Yi, J. Mater. Chem. A, 2015, 3, 5617.

53 X. Chen and S. S. Mao, Chem. Rev., 2007, 107, 2891.

54 F. J. Heiligtag, W. Cheng, V. R. de Mendonça, M. J. Süess, K. Hametner, D. Günther, C. Ribeiro and M. Niederberger, Chem. Mater., 2014, 26, 5576.

55 X. Z. Li, F. B. Li, C. L. Yang and W. K. Ge, J. Photochem. Photobiol. A, 2001, 141, 209. 
56 P. V. Kamat, J. Phys. Chem. B, 2002, 106, 7729.

57 R. O. da Silva, F. J. Heiligtag, M. Karnahla., H. Junge, M. Niederberger and S. Wohlra, Catalysis Today, 2015, 246, 101.

58 H. J. Zhang, C. Lin, T. Han, F. P. Du, Y. H. Zhao, X. P. Li and Y. H. Sun, ACS Sustainable Chem. Eng., 2016, 4, 6277.

59 C. Ziegler, S. Klosz, L. Borchardt, M. Oschatz, S. Kaskel, M. Friedrich, R. Kriegel, T. Keilhauer, M. Armbrüster and A. Eychmüller, Adv. Funct. Mater., 2016, 26, 1014.

60 A. Freytag, M. Colombo and N. C. Bigall, Z. Phys. Chem., 2017, 231, 63.

61 C. J. Murphy, Anal. Chem., 2002, 74, 520

62 J. P. Yuan, W. W. Guo, X. R. Yang and E. K. Wang, Anal. Chem., 2009, 81, 362.

63 N. Gaponik, J. Mater. Chem., 2010, 20, 5174.

64 Q. Yao and S. L. Brock, Nanotechnology, 2010, 21, 115502.

65 J. P. Yuan, D. Wen, N. Gaponik and A. Eychmüller, Angew. Chem. Int. Ed., 2013, 52, 976.

66 D. Wen, W. Liu, A.-K. Herrmann and A. Eychmüller, Chem.Eur. J., 2014, 20, 4380.

67 D. Wen, W. Liu, A.-K. Herrmann, D. Haubold, M. Holzschuh, F. Simon and A. Eychmüller, Small, 2016, 12, 2439.

68 M. V. Rekharsky and Y. Inoue, Chem. Rev., 1998, 98, 1875.

69 D. Wen, W. Liu, D. Haubold, C. Z. Zhu, M. Oschatz, M. Holzschuh, A. Wolf, F. Simon, S. Kaskel and A. Eychmüller, ACS Nano, 2016, 10, 2559.

70 W. N. He, G. Y. Li, S. Q. Zhang, Y. Wei, J. Wang, Q. W. Li and X. T. Zhang, ACS Nano, 2015, 9, 4244.

71 X. J. Xu, R. R. Wang, P. Nie, Y. Cheng, X. Y. Lu, L. J. Shi and J. Sun, ACS Appl. Mater. Interfaces, DOI: 10.1021/acsami.7b02087.

72 Q. Q. Sun, M. W. Xu, S. J. Bao and C. M. Li, Nanotechnology, 2015, 26, 115602 .

73 L. H. Zhi, W. Zuo, F. J. Chen and B. D. Wang, ACS Sustainable Chem. Eng., 2016, 4, 3398.

74 V. L. Colvin, M. C. Schlamp and A. P. Alivisatos, Nature, 1994, 370, 354.

75 B. A. Ridley, B. Nivi and J. M. Jacobson, Science, 1999, 286, 746.

76 G. Konstantatos, I. Howard, A. Fischer, S. Hoogland, J. Clifford, E. Klem, L. Levina and E. H. Sargent, Nature, 2006, 442, 180

77 I. Gur, N. A. Fromer, M. L. Geier and A, P. Alivisatos, Science, 2005, 310, 462.

78 J. Wu, S. M. Chen, A. Seeds and H. Y. Liu, J. Phys. D: Appl. Phys., 2015, 48, 363001.

79 N. Gaponik, A. Wolf, R. Marx, V. Lesnyak, K. Schilling and A. Eychmüller, Adv. Mater., 2008, 20,4257.

80 L. Korala, L. Li and S. L. Brock, Chem. Commun., 2012, 48, 8523.

81 J. N. D. Freitas, L. Korala, L. X. Reynolds, S. A. Haque, S. L. Brock and A. F. Nogueira, Phys. Chem. Chem. Phys., 2012, $14,15180$.

82 L. Korala, Z. J. Wang, Y. Liu, S. Maldonado and S. L. Brock, ACS Nano, 2013, 7,1215.

83 V. Lesnyak, A. Wolf, A. Dubavik, L. Borchardt, S.V. Voitekhovich, N. Gaponik, S. Kaskel and A. Eychmüller, J. Am. Chem. Soc., 2011, 133, 13413.

84 T. Hendel, V. Lesnyak, L. Kühn, A.-K. Herrmann, N. C. Bigall, L. Borchardt, S. Kaskel, N. Gaponik and A. Eychmüller, Adv. Funct. Mater., 2013, 23, 1903.

85 L. Nahar, R. J A. Esteves, S. Hafiz, Ü. Özgür and I. U. Arachchige, ACS Nano, 2015, 9,9810.

86 R. P. Schwarzenbach, B. I. Escher, K. Fenner, T. B. Hofstetter, C. A. Johnson, U. von Gunten and B. Wehrli, Science, 2006, 313,1072.

87 Q. Yao, I. U. Arachchige and S. L. Brock, J. Am. Chem. Soc., 2009, 131, 2800
88 I. R. Pala and S. L. Brock, ACS Appl. Mater. Interfaces, 2012, 4, 2160.

89 S. M. Jung, H. Y. Jung, W. J. Fang, M. S. Dresselhaus and J. Kong, Nano Lett., 2014, 14, 1810.

90 B. Wang, H. Wu, L. Yu, R. Xu, T. T. Lim and X. W. Lou, Adv. Mater., 2012, 24, 1111.

91 X. F. Yu, J. W. Liu, H. P. Cong, L. Xue, M. N. Arshad, H. A. Albar, T. R. Sobahi, Q. Gao and S. H. Yu, Chem. Sci., 2015, 6, 2511.

92 W. Cheng, F. Rechberger and M. Niederberger, ACS Nano, 2016, 10, 2467.

93 W. Y. Zhai, C. X. Wang, P. Yu, Y. X. Wang and L. Q. Mao, Anal. Chem., 2014, 86, 12206.

94 Z. N. Liu, K. L. Xu, P. She, S. Y. Yin, X. D. Zhu, H. Sun, Chem. Sci., 2016, 7, 1926.

95 X. N. Gao, R. J. A. Esteves, L. Nahar, J. Nowaczyk and I. U. Arachchige, ACS Appl. Mater. Interfaces, 2016, 8, 13076.

96 S. M. Jung, D. J. Preston, H. Y. Jung, Z. T. Deng , E. N. Wang and J. Kong, Adv. Mater., 2016, 28, 1413.

97 Y. Tang, S. Gong, Y. Chen, L. W. Yap and W. L. Cheng, ACS Nano, 2014, 8, 5707.

98 M. Koirala, H. Wang, M. Pokharel, Y. C. Lan, C. F. Guo, C. Opeil and Z. F. Ren, Nano Lett., 2014, 14, 5016.

99 S. Ganguly and S. L. Brock, J. Mater. Chem., 2011, 21, 8800.

100 D. James, X. Lu, A. C. Nguyen, D. Morelli and S. L. Brock, J. Phys. Chem. C, 2015, 119, 4635.

101 W. Dong, W. Rhine, G. Caggiano, O. R. Evans, G. Gould, J. White, J. Sharp, P. Gilbert, S. Ganguly and S. L. Brock, MRS Online Proc. Libr. 2011, 1306, mrsf10-1306-bb12-02.

102 S. Ganguly, C. Zhou, D. Morelli, J. Sakamoto and S. L. Brock, J. Phys. Chem. C, 2012, 116,17431. 